\title{
Lymphadenopathy and lymph node infarction as a result of gold injections
}

\author{
C Roberts, P J Batstone, J R Goodlad
}

\begin{abstract}
This report describes a case of lymphadenopathy and lymph node infarction as a consequence of intramuscular gold administered to a patient suffering from rheumatoid arthritis, to highlight this rare association. A 34 year old woman with a four year history of rheumatoid arthritis affecting multiple joints was started on intramuscular gold injections after little response to anti-inflammatory medication. After her sixth injection the patient developed enlarged neck and axillary lymph nodes. Biopsy showed subtotal infarction of a reactive node, confirmed by histochemical, immunohistochemical, and molecular techniques. The patient continued to suffer from rheumatoid arthritis with no evidence of malignant lymphoma after three years. This case provides strong evidence that lymphadenopathy with infarction is a rare complication of gold injections. In such a situation, it is particularly important to exclude a diagnosis of lymphoma, because this is the most common cause of spontaneous lymph node infarction. This can be achieved through awareness of the association, and by the use of ancillary histochemical, immunohistochemical, and molecular techniques on the biopsy material.

(F Clin Pathol 2001;54:562-564)
\end{abstract}

Keywords: lymph node infarction; gold; rheumatoid arthritis

Although most of the side effects of gold injections are well recognised, only rarely has lymphadenopathy been described as part of an adverse reaction. ${ }^{1-3}$ Spontaneous infarction of superficial lymph nodes is also an uncommon occurrence, especially in patients who are not subsequently found to have malignant lymphoma. ${ }^{45}$ Here, we describe a case of lymph node infarction presenting as lymphadenopathy during a course of intramuscular gold injections, an association described only once previously, ${ }^{2}$ to draw attention to this rare association.

\section{Case report}

The patient was a 34 year old woman with a four year history of progressive, seropositive rheumatoid arthritis affecting her hands, fingers, wrists, knees, and hips. Her past medical history included Peutz-Jeghers syndrome and an ovarian mucinous cystadenoma. Treatment of the arthritis had initially been with non-steroidal, anti-inflammatory drugs, discontinued because of gastric symptoms, and intra-articular steroid injections to the left shoulder, followed by sulfasalazine and oral prednisolone. There was little response to the latter two drugs and intramuscular gold (sodium aurothiomalate), $50 \mathrm{mg} /$ week, was started. Shortly after receiving her sixth injection the patient presented with a tender enlarged lymph node measuring $2 \times 2 \mathrm{~cm}$ in the right posterior triangle of the neck, as well as non-tender pre-auricular and left axillary lymphadenopathy. A biopsy of the enlarged neck node showed lymph node infarction. The gold injections were discontinued and the lymphadenopathy gradually resolved over the next two months. Three years later the patient was alive with no evidence of lymphadenopathy, but with persistently active rheumatoid arthritis.

\section{Materials and methods}

Tissue sections ( $4 \mu \mathrm{m}$ thick) from paraffin wax embedded tissue were stained routinely with haematoxylin and eosin and immunohistochemically using a streptavidin-biotin complex immunoperoxidase technique and the following antibodies: anti-CD3 (polyclonal; Dako, Copenhagen, Denmark; diluted 1/100), antiCD20 (monoclonal; Dako; diluted 1/400), anti-CD45 (monoclonal; Dako; diluted 1/400), and anti-CD45RO (monoclonal; Dako; diluted $1 / 50)$. Secondary antibodies and the final layer were all obtained from Dako. Antigen retrieval was performed for the detection of all antigens by pressure cooking sections in citric acid buffer.

A polymerase chain reaction (PCR) for immunoglobulin heavy chain and $T$ cell receptor $\gamma$ gene rearrangements was performed on DNA extracted from $6 \times 5 \mu \mathrm{m}$ sections cut from routinely processed paraffin wax embedded tissue; the former using the primer pair FR3A and LJH (Perkin-Elmer, Warrington, $\mathrm{UK}){ }^{6}$ and the latter using primers $\mathrm{V} \gamma 11$, $\mathrm{V} \gamma 101, \mathrm{~J} \gamma 12$, and Jp12 (Perkin-Elmer) in two multiplex reactions. ${ }^{7}$ DNA amplification was performed in a total volume of $25 \mu \mathrm{l}$ containing $1 \mu \mathrm{l}$ extracted DNA, $2.5 \mu \mathrm{l}$ buffer IV, $1.5 \mu \mathrm{l}$ $\mathrm{MgCl}_{2}(25 \mathrm{mM}), 0.75 \mu \mathrm{dNTPs}(20 \mathrm{mM})$ (all ABgene Epsom, Surrey, UK), and $1.25 \mu \mathrm{l}$ of each primer. After five minutes denaturation at $100^{\circ} \mathrm{C}, 0.5 \mathrm{U}$ enzyme (Thermoprime+; ABgene) was added. Thirty PCR cycles were then undertaken $\left(94^{\circ} \mathrm{C}\right.$ for one minute, $60^{\circ} \mathrm{C}$ for one minute and 30 seconds), followed by a final extension step at $72^{\circ} \mathrm{C}$ for five minutes. DNA from known B and T cell non-Hodgkin's lymphomas and reactive lymph nodes were used as positive and negative controls, respectively. The final products were visualised by UV transmission of ethidium bromide stained $8 \%$ polyacrylamide gels. 


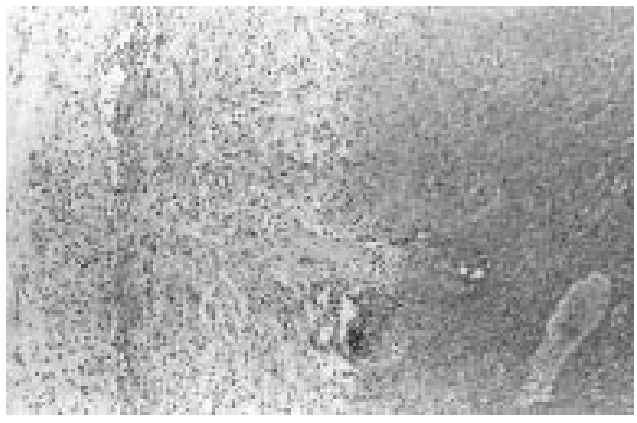

Figure 1 Haematoxylin and eosin stained section showing infarcted lymphoid tissue on the right and a peripheral rim of organising granulation tissue in the region of the subcapsular sinus.

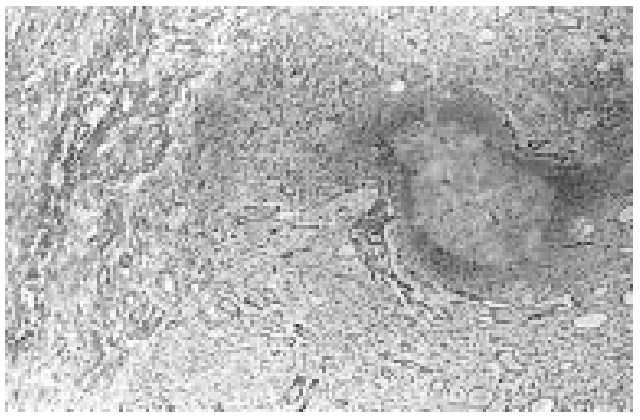

Figure 2 A reticulin stain showing preservation of the lymph node architecture and confirming the presence of follicular structures.

\section{Pathological findings}

Sections of the lymph node showed subtotal, but almost complete, infarction with only a peripheral rim of organising granulation tissue present in the region of the subcapsular sinus (fig 1), and a small focus of residual viable lymphoid tissue showing features of follicular hyperplasia. The centre of the node was filled with the ghost outlines of necrotic cells. In cortical areas, there were foci in which the nuclei of the dead cells were better preserved and appeared to be forming mantles around necrotic germinal centres, giving an impression that reactive follicles had previously been present. This interpretation was supported by a reticulin stain, which also showed preservation of the normal nodal architecture (fig 2). Immunohistochemical stains also emphasised the presence of necrotic $B$ cell follicles surrounded by $\mathrm{T}$ cell areas, in keeping with normal nodal architecture. Nothing to suggest an underlying lymphoma was identified and this was borne out by PCR studies, which showed polyclonal rearrangements of immunoglobulin and $\mathrm{T}$ cell receptor genes.

\section{Discussion}

Spontaneous infarction of lymph nodes is rare; it has been estimated that one case of lymph node infarction will be encountered in every 13000 routine surgical specimens. ${ }^{4}$ The most frequent association is with malignant lymphoma, accounting for approximately $40 \%$ of cases in unselected series ${ }^{4}$ and $97 \%$ of cases in specialist units. ${ }^{8}$ Even when not apparent at the time of initial presentation with an infarcted node, subsequent biopsy will reveal malignant lymphoma in a large number of patients. ${ }^{48}$

In our case, lymphoma can almost certainly be ruled out as a cause of the lymph node infarction. It was not evident at the time of biopsy even when immunohistochemical and molecular studies were undertaken, both of which have been demonstrated as useful in diagnosing lymphoma in completely infarcted nodes. ${ }^{9}{ }^{10}$ Moreover, in cases where lymphoma manifests itself in a biopsy taken after one showing lymph node infarction, it invariably does so within two years. ${ }^{4}$ Our patient was alive with no evidence of lymphoma three years after initial presentation. Other potential causes of lymph node infarction include vascular thrombosis, infections, and mechanical pressure. ${ }^{4}$ There was no evidence, either clinically or in the biopsy specimen, that any of these factors were at work in the current case. All the above findings, coupled with the complete resolution of symptoms after the cessation of gold injections, argue strongly that the latter were responsible for infarction of the lymph node.

Lymph node infarction occurring during the course of gold injections has only been reported once. ${ }^{2}$ In addition, two patients have been described in whom lymphadenopathy developed as part of a reaction to gold injections. ${ }^{13}$ Biopsy was only undertaken in one of these cases and this was said to show "reactive cortical hyperplasia". ' In all these patients, including our patient, the lymphadenopathy was tender and developed in neck nodes, either in isolation or as part of a more generalised lymph node enlargement, always within a few weeks of initiating treatment. Similarly, all cases underwent complete resolution of symptoms on cessation of treatment, either spontaneously (our case, and Lowthian ${ }^{1}$ and Prichanond and Skosey ${ }^{3}$ ) or with concomitant steroid administration. ${ }^{2}$ In the previously described case of gold induced lymph node infarction it was postulated that a vasculitis might have been the underlying pathogenetic mechanism. ${ }^{2}$ However, there was no firm evidence of such a process in that case or in the one that we currently describe.

In summary, this case emphasises that lymphadenopathy might occur as part of a reaction to gold injections. Although lymph node enlargement commonly occurs in rheumatoid patients, the timing of its onset in the cases described and the resolution of symptoms on withdrawal of the drug mean that the relation is unlikely to be coincidental. Furthermore, gold injections appear to be a rare cause of lymph node infarction, although the mechanism leading to infarction remains to be determined.

The authors would like to thank Dr C Yiu, Hurley Clinic, London for providing follow up clinical information on this patient.

1 Lowthian PJ. Hepatotoxicity with aurothioglucose therapy. Arthritis Rheum 1984;27:230-2.

2 Rothschild B, Marshall A. Lymphadenopathy and lymph node infarction in the course of gold therapy. Am $\mathscr{f} \mathrm{Med}$ 1986;80:537-9. 
3 Prichanond S, Skosey JL. Gold and liver biopsy [letter]. Ann Intern Med 1978;88:579.

Maurer M, Schmid U, Davies JD, et al. Lymph-node infarction and malignant lymphoma: a multicentre survey of European, English and American cases. Histopathology 1986;10:571-88

5 Davies JD, Stansfeld AG. Spontaneous infarction of superficial lymph nodes. I Clin Pathol 1972;25:689-96

6 Wan JH, Trainor KJ, Brisco MJ, et al. Monoclonality in B cell lymphoma detected in paraffin wax embedded sections using the polymerase chain reaction. F Clin Pathol 1990;43: 888-90.
7 McCarthy KP, Sloane JP, Kabarowski JHS, et al. A simplified method of detection of clonal rearrangements of the T-cell
receptor- $\gamma$ chain gene. Diagn Mol Pathol 1992;1:173-9.

8 Cleary KR, Osborne BM, Butler JJ. Lymph node infarction foreshadowing malignant lymphoma. Am f Surg Pathol 1982;6:435-42.

9 Norton AJ, Ramsay, AD, Isaacson PQ. Antigen preservation in infarcted lymphoid tissue. Am $¥$ Surg Pathol 1988;12: 759-67.

10 Laszewski MJ, Belding PJ, Feddersen RM, et al. Clonal immunoglobulin gene rearrangement in the infarcted lymph node syndrome. Am f Clin Pathol 1991;96:116-20.

\section{What's in the next issue}

\section{Future content}

See which articles have just been accepted for publication and preview the table of contents for the next issue a month before it is published

www.jclinpath.com 